\title{
Ascorbic Acid as An Effective Antioxidant Additive to Enhance the Efficiency and Stability of Pb/Sn-Based Binary Perovskite Solar Cells
}

Xiaobao Xu, ${ }^{a}$ Chu-Chen Chueh, ${ }^{a}$ Zhibin Yang, ${ }^{a}$ Adharsh Rajagopal, ${ }^{a}$ Jingqi Xu, ${ }^{a}$ Sae Byeok Jo ${ }^{a}$ and Alex K.-Y. Jen ${ }^{a, b} *$

${ }^{a}$ Department of Materials Science and Engineering, University of Washington, Seattle, WA, 98195-2120, USA

${ }^{\mathrm{b}}$ Department of Biology and Chemistry and Department of Physics and Materials Science, City University of Hong Kong, Kowloon, Hong Kong

*Corresponding author. E-mail: ajen@uw.edu

KEYWORDS: $\mathrm{Sn}^{2+}$ oxidation; Perovskite solar cell; Ascorbic acid; Stability

\begin{abstract}
Realizing efficient organic/inorganic hybrid perovskite solar cells (PVSCs) with reduced toxic lead $(\mathrm{Pb})$ content is important for developing sustainable clean photovoltaics. The vigorous progress made recently for tin ( $\mathrm{Sn})$ - and $\mathrm{Pb} / \mathrm{Sn}$-based PVSCs has drawn considerable attention because of their potential to reduce $\mathrm{Pb}$ content in perovskites. However, the inferior chemical stability of $\mathrm{Sn}$ to $\mathrm{Pb}$ element necessitates more sophisticated morphological and processing engineering of Sn-containing PVSCs in order to achieve high performance and stability. We have recently discovered that ascorbic acid (AA) can serve as a simple but effective additive to simultaneously enhance the performance and stability of Sn-containing PVSCs. It is revealed that AA as a commonly known antioxidant can retard the oxidation of Sn-containing precursor solution of perovskite while modulate its perovskite crystallization by forming intermediate complexes. This is evidenced by the prolonged photogenerated carrier lifetime (182.7 ns) of its derived $\mathrm{MA}_{0.5} \mathrm{FA}_{0.5} \mathrm{~Pb}_{0.5} \mathrm{Sn}_{0.5} \mathrm{I}_{3}$ film. As a result, a high PCE of $14.01 \%$ with improved stability can be realized in the binary metal PVSC with AA as additive, outperforming the value $(12.18 \%)$ of the control device processed with the regular $\mathrm{SnF}_{2}$ additive.
\end{abstract}




\section{Introduction}

Due to recent breakthrough made in perovskite solar cells (PVSCs),[1-2] solution processable organic/inorganic hybrid halide perovskites have become one of the most promising photovoltaic materials for solar energy.[3-14] However, there are several critical concerns such as toxic lead $(\mathrm{Pb})$ contaminant and stability that need to be addressed before PVSC can be considered for commercialization. So far, all of the high-performance PVSCs reported so far are mainly based on the organolead halide perovskite family $\left(\mathrm{RPbX}_{3}, \mathrm{R}=\right.$ methylammonium $\left(\mathrm{MA}^{+}\right) /$formamidinium $\left.\left(\mathrm{FA}^{+}\right) ; \mathrm{X}=\mathrm{I}^{-} / \mathrm{Br}^{-}\right)$. However, $\mathrm{Pb}$ has been proven to be very harmful for human health.[15-16] Therefore, it is urgent to develop other perovskite alternatives with reduced $\mathrm{Pb}$ content to ensure environmentally friendly and sustainable photovoltaics can be developed.

Nevertheless, it is very challenging to substitute $\mathrm{Pb}$ without affecting the resulting semiconducting properties of the derived hybrid perovskites. Until now, Tin ( $\mathrm{Sn}$ ) element in the same Group 14 with $\mathrm{Pb}$ is the most feasible alternative, which has similar $n s^{2} n p^{2}$ electron configuration and coordination geometry to those of $\mathrm{Pb}$ but possesses a smaller radius and lower toxicity.[17-18] Initially, researchers have tried to replace $\mathrm{Pb}^{2+}$ with $\mathrm{Sn}^{2+}$ completely to form pure $\mathrm{RSnX}_{3}$ perovskites. However, these materials encountered significantly reduced efficiency due to the oxidative instability of $\mathrm{Sn}^{2+}$ and poor morphology of derived perovskite thin films.[19] Oxidation of $\mathrm{Sn}^{2+}$ to $\mathrm{Sn}^{4+}$ will deteriorate the semiconducting properties and morphology of pristine $\mathrm{RPbX}_{3}$ to result in reduced device performance and stability.

Recently, several studies on $\mathrm{Pb}-\mathrm{Sn}$ binary metal perovskites have been reported with significantly improved PCEs and stability of Sn-containing PVSCs.[20-24] These results unraveled that partial substitution of $\mathrm{Pb}$ with $\mathrm{Sn}$ in pervoskite composition might be a valid strategy to develop high-performance Sn-containing PVSCs since it can preserve the superior semiconducting properties of pristine $\mathrm{RPbX}_{3}$ perovskites.[21-24] Note that the band gap $\left(\mathrm{E}_{\mathrm{g}}\right)$ 
of $\mathrm{RPb}_{1-\mathrm{x}} \mathrm{Sn}_{\mathrm{x}} \mathrm{I}_{3}$ can be tuned to harvest lower energy photons by manipulating the corresponding $\mathrm{Pb} / \mathrm{Sn}$ ratios, which provides a great opportunity to develop low $\mathrm{E}_{\mathrm{g}}$ PVSCs and all perovskite tandem cells.[25]

Owing to the oxidative instability of $\mathrm{Sn}^{2+}$, more elaborate morphological and device engineering are required for binary metal perovskites compared to its $\mathrm{Pb}$-counterpart.[20-24] Lately, a solvent additive, $\mathrm{SnF}_{2}$, has been reported to somewhat relieve the $\mathrm{Sn}$ oxidation and result in significantly improved device performance and stability.[17] However, more recent results have unveiled that the added $\mathrm{SnF}_{2}$ will engender phase separation in the prepared films due to its inhomogeneous dispersion during film evolution.[26] Another factor that also affects the morphology of Sn-containing perovskites is the fast reaction rate between $\mathrm{SnI}_{2}$ and MAI/FAI, which often causes inhomogeneity of the prepared films.[23-24] These problems reflect the needs of developing better and reliable processing techniques for making binary perovskites to realize efficient and stable PVSCs.

In this study, we have for the first time introduced a common antioxidant, ascorbic acid (AA), as an additive to assist the processing of Sn-based perovskites. It is revealed that AA can effectively retard the oxidation of binary perovskite precursor solutions while simultaneously modulate the kinetics of perovskite crystallization by forming intermediate complexes. As a result, a high PCE of $14.01 \%$ with improved stability can be realized in a $\mathrm{MA}_{0.5} \mathrm{FA}_{0.5} \mathrm{~Pb}_{0.5} \mathrm{Sn}_{0.5} \mathrm{I}_{3}$ PVSC processed with AA additive, outperforming the value (12.18\%) of the control device processed using regular $\mathrm{SnF}_{2}$ additive. In addition, the binary perovskite $\left(\mathrm{MA}_{0.5} \mathrm{FA}_{0.5} \mathrm{Sn}_{0.5} \mathrm{~Pb}_{0.5} \mathrm{I}_{3}\right.$ herein) is disclosed to possess a distinctly different decomposition route from the pristine $\mathrm{MAPbI}_{3}, \mathrm{FAPbI}_{3}$, and $\mathrm{RSnX}$ 列 based on the X-ray diffraction (XRD) analysis.

\section{Experimental Section}




\subsection{Preparation of materials}

All chemicals and reagents were purchased from Sigma-Aldrich without further purification. All solutions are filtered with a $0.45 \mu \mathrm{m}$ PTFE filter prior to use.

\subsection{Fabrication of solar cells}

ITO glass was first cleaned by detergent, followed by ultra-sonication with detergent, DI water, acetone, and isopropanol for $10 \mathrm{~min}$ immersion, respectively. Then, the substrates were dried by nitrogen flow and treated with ultraviolet-ozone for 20 min before the deposition of PEDOT:PSS. The PEDOT:PSS (Al 4083) solution was spin-coated onto the cleaned ITO glass at $5000 \mathrm{rpm}$ for $30 \mathrm{~s}$ and annealed at $150{ }^{\circ} \mathrm{C}$ for $10 \mathrm{~min}$ in air. To prepare the $\mathrm{MAPbI}_{3}$ perovskite precursor solution, MAI (159 mg) and $\mathrm{PbI}_{2}(462 \mathrm{mg})$ were dissolved in a mixed solvent of DMF $(630 \mu \mathrm{L})$ and DMSO $(70 \mu \mathrm{L})$ while FAI $(172 \mathrm{mg})$ and $\mathrm{SnI}_{2}(372 \mathrm{mg})$ were dissolved in a mixed solvent of DMF $(800 \mu \mathrm{L})$ and DMSO $(200 \mu \mathrm{L})$ to constitute the $\mathrm{FASnI}_{3}$ precursor solution. Additives $\left(\mathrm{SnF}_{2}\right.$ or $\left.\mathrm{AA}\right)$ was added with $10 \%$ mole ratio in $\mathrm{FASnI}_{3}$ precursor solution. Finally, the binary perovskite precursor solution was prepared by mixing $\mathrm{MAPbI}_{3}(70 \mu \mathrm{L})$ and $\mathrm{FASnI}_{3}(100 \mu \mathrm{L})$ precursor solutions. Afterward, the perovskite films were spin-coated onto the PEDOT:PSS layer at $5000 \mathrm{rmp}$ for $35 \mathrm{~s}$ in the glove box. Toluene (700 $\mu \mathrm{L})$ was dripped in-situ onto the substrate at the $10^{\text {th }} \mathrm{s}$. Afterward, the perovskite films were annealed at $100{ }^{\circ} \mathrm{C}$ for $3 \mathrm{~min}$. PCBM solution $(20 \mathrm{mg} / \mathrm{ml}$ in chlorobenzene $)$ was then spin-coated onto the perovskite film at $2000 \mathrm{rpm}$ for $30 \mathrm{~s}$, followed by the deposition of bis- $\mathrm{C}_{60}$ layer $(2 \mathrm{mg} / \mathrm{ml}$ in isopropyl alcohol, spin-coated at $3000 \mathrm{rpm}$ for $35 \mathrm{~s}$ ). Finally, $\mathrm{Ag}$ electrode with a thickness of $120 \mathrm{~nm}$ was evaporated under high vacuum $\left(<2 \times 10^{-6} \mathrm{Torr}\right)$.

\subsection{Characterization}

XRD was measured by X-ray diffractometer (Bruker F8 Focus Powder for regular XRD and Bruker D8 Discover 2-D XRD for refined XRD). SEM was measured by FEI Sirion and operated at $5 \mathrm{kV}$. The absorption spectra were measured Varian Cary 5000 UV-Vis 
spectrometer. The PL decay measurement is conducted with IR detector (id 220-FR-MMF, id Quatique SA Geneva/Switzerland). The $J$ - $V$ curves were recorded by a Keithley 2400 Source measurement unit, a $450 \mathrm{~W}$ xenon lamp was used to produce light, the light intensity of $\left(100 \mathrm{~mW} / \mathrm{cm}^{2}\right)$ was calibrated by a standard Si photodiode detector. The EQE spectra were measured by a joint system of monochromated $450 \mathrm{~W}$ xenon lamp (Oriel) and a sourcemeter (Keithley 2400), which calculated using a calibrated Si photodiode (OSI-Optoelectronics), and all solar cells were studied without any encapsulation in stability test. The M-S plot and admittance spetrca were collected by CHI660E electrochemical work station.

\section{Results and discussion}

As a solvent additive, AA not only can retard $\mathrm{Sn}^{2+}$ oxidation, its counter anion can also form iodoplumbate complexes to modulate binary perovskite crystallization.[27-28] To evaluate the anti-oxidation capability of $\mathrm{AA}, \mathrm{FASnI}_{3}$ precursor solutions with varied amounts of AA were prepared and stored in air for comparison (Figure 1). Considering the influence of $\mathrm{Sn}^{2+}$ concentration on oxidizing rate, all the solutions contained $10 \mathrm{~mol} \% \mathrm{SnF}_{2}$. Initially, the precursor solution exhibited a light-yellow color. Once exposed to air, the surface region of the precursor solution immediately turned into dark red color as a result of the rapid oxidation of $\mathrm{Sn}^{2+}$ to $\mathrm{Sn}^{4+}$, revealing the sensitivity of $\mathrm{Sn}^{2+}$ to oxygen. However, the conversion rate is gradually decreased by increasing the AA concentration. As shown, the pristine solution with $10 \mathrm{~mol} \% \mathrm{SnF}_{2}$ completely degraded after 12 -min, whereas the $10 \mathrm{~mol} \%$ and $15 \mathrm{~mol} \% \mathrm{SnF}_{2}$-containing solutions with $\mathrm{AA}$ additive extended the degradation time to over 16 min. This result manifests the potential of using AA in retarding $\mathrm{Sn}^{2+}$ oxidation in the precursor solution.

Presented in Figure S1 are the NMR spectra of AA and AA with $\mathrm{SnI}_{2}$ in $\mathrm{D}_{6}$-DMSO solvent. As can be seen, the $\mathrm{H}_{\mathrm{b}}$ of AA disappeared after adding $\mathrm{SnI}_{2}$ into the solution, 
suggesting an efficient coordination between them. It can be envisioned that the counter anion of AA serves as a conjugated Lewis base to form adduct with $\mathrm{SnI}_{2}$ which is a Lewis acid. Such intermediate iodoplumbate complexes have been shown to influence the perovskite crystallization kinetics during film formation.[28] The intermediate complexes may also retard $\mathrm{Sn}^{2+}$ oxidation by quenching the singlet oxygen via its $\mathrm{C}=\mathrm{C}$ double bond.[29] Its oxidized product (dehydro-ascorbic acid) might also act as a stabilizer and capping ligand to passivate the defect-induced traps at the perovskite grain boundaries.[30]

To validate the efficacy of AA additive in $\mathrm{Pb}-\mathrm{Sn}$ binary perovskite system, we have chosen $\mathrm{MA}_{0.5} \mathrm{FA}_{0.5} \mathrm{~Pb}_{0.5} \mathrm{Sn}_{0.5} \mathrm{I}_{3}$ as the model composition based on the following reasons: i) $50 \% \mathrm{Sn}$ substituted device possesses decent device performance and a suitable low $\mathrm{E}_{\mathrm{g}}$ of $\sim 1.2 \mathrm{eV}$ that is ideal for fabricating all perovskite tandem solar cells[23-24]; ii) partial replacement of $\mathrm{MA}^{+}$ with $\mathrm{FA}^{+}$in $\mathrm{Pb} / \mathrm{Sn}$-based perovskite is beneficial for further retarding $\mathrm{Sn}^{2+}$ oxidation.[23]

As reported by us and others[20,23-26], rapid reaction between $\mathrm{SnI}_{2}$ and MAI/FAI adversely affects the morphology and film quality of $\mathrm{Pb} / \mathrm{Sn}$-based perovskites. Therefore, several recent studies have focused more on morphological engineering of $\mathrm{Pb} / \mathrm{Sn}$-based perovskites to improve performance.[22-24] Among which, the solvent-washing based deposition technique is the most successful one; therefore, it is adopted in this study.[31] Shown in Figure $\mathbf{2}$ are the scanning electron microscopy (SEM) images of the $\mathrm{MA}_{0.5} \mathrm{FA}_{0.5} \mathrm{~Pb}_{0.5} \mathrm{Sn}_{0.5} \mathrm{I}_{3}$ films processed with $\mathrm{SnF}_{2}$ and $\mathrm{AA}$ additives (molar ratio to $\mathrm{SnI}_{2}, 10 \%$ ), respectively, wherein both films showed homogeneous morphology with densely packed crystalline domains $(200-400 \mathrm{~nm})$ and good film coverage. However, for the $\mathrm{MA}_{0.5} \mathrm{FA}_{0.5} \mathrm{~Pb}_{0.5} \mathrm{Sn}_{0.5} \mathrm{I}_{3}$ film processed with $\mathrm{SnF}_{2}$ additive, some white spots were observed, which should be attributed to the phase segregation of $\mathrm{SnF}_{2}$ discussed earlier.[25] Whereas, the film processed with AA additive displayed a spot-free morphology, suggesting minimal impact of AA on resulting morphology. This can be ascribed to its capability of forming 
intermediate state with $\mathrm{PbI}_{2} / \mathrm{SnI}_{2}$ to enable its uniform dispersion during film evolution. This result demonstrates that AA can be a simple but effective additive to assist processing of binary perovskites.

To examine the stability of these prepared films, their optical properties and XRD characteristics as a function of storage time in ambient (humidity: $\sim 40-60 \%$; temperature: $~ 20$ ${ }^{\circ} \mathrm{C}$ ) were recorded for comparison. Figure 3a illustrates the light harvesting efficiency (LHE) of the prepared $\mathrm{MA}_{0.5} \mathrm{FA}_{0.5} \mathrm{~Pb}_{0.5} \mathrm{Sn}_{0.5} \mathrm{I}_{3}$ films processed with different additives. For the fresh films, a clear absorption onset rising from $1000 \mathrm{~nm}$ with an estimated $\left(\mathrm{E}_{\mathrm{g}}\right)$ of $1.24 \mathrm{eV}$ can be observed; whereas, it became evanescent as the storage time in air increases. This might be due to the formation of sub- $\mathrm{E}_{\mathrm{g}}$ states as a result of $\mathrm{Sn}^{2+}$ oxidation to $\mathrm{Sn}^{4+}$ or to the scattering induced by the degraded morphology.[24] However, the film processed with AA showed a much slower rate in decrease of absorption onset than that of the film derived from $\mathrm{SnF}_{2}$, affirming the effectiveness of AA additive in providing better anti-oxidative function than commonly used $\mathrm{SnF}_{2}$ additive. These additive effects were also compared in the pure $\mathrm{FASnI}_{3}$ system as shown in Figure $\mathbf{S 2}$, wherein the AA-derived $\mathrm{FASnI}_{3}$ showed the slowest rate in decreasing absorption band edge among the prepares films

Figure $3 \mathrm{~b}$ and $\mathbf{3 c}$ display the corresponding XRD characteristics and pictures of the studied $\mathrm{MA}_{0.5} \mathrm{FA}_{0.5} \mathrm{~Pb}_{0.5} \mathrm{Sn}_{0.5} \mathrm{I}_{3}$ films. As shown, all the fresh dark brown color perovskite films gradually turned into red color after exposing to air for 4 days due to the oxidation. It is important to note that this color change accompanied with the broadened full-width-at-halfmaximum (FWHM) of the XRD characteristic peaks, indicating decrease of crystal size based on the Scherrer equation.[32] In addition to the broadened peaks, the edge of the films became transparent after being stored in air for 12 days. Eventually, both films became completely transparent without peaks showing the characteristics of the yellow polymorph FASnI 3 at $12.5^{\circ}$ or $\mathrm{PbI}_{2}$ for the degraded $\mathrm{Pb}$-based perovskites.[33] The UV-vis absorption 
spectra of the decomposed species are shown in Figure S3. This result indicates that a new decomposition pathway might occur in $\mathrm{Pb}-\mathrm{Sn}$ binary metal perovskites, which is different to those for $\mathrm{RPbX}_{3}$ or $\mathrm{RSnX}_{3}$ perovskites.

For the $\mathrm{Pb} / \mathrm{Sn}$-based perovskite, $\mathrm{Sn}$ oxidation has been reported to create $\mathrm{Sn}$ vacancy that serves as charge-trapping sites to induce severe charge recombination. Therefore, carrier lifetime of both prepared $\mathrm{MA}_{0.5} \mathrm{FA}_{0.5} \mathrm{~Pb}_{0.5} \mathrm{Sn}_{0.5} \mathrm{I}_{3}$ films on glass were also characterized using photoluminescence (PL) decay transient spectroscopy at room temperature with a blue light exciting source of $470 \mathrm{~nm}$ and an IR detector to ascertain the optoelectronic quality of these prepared films. Illustrated in Figure 4 are the corresponding PL decay curves, wherein the time constant $(\tau)$ associating with the lifetime of carrier was obtained from exponential fitting with $92.5 \mathrm{~ns}$ and $182.7 \mathrm{~ns}$ for the $\mathrm{SnF}_{2}$-derived film and AA-derived film, respectively. This result suggests that charge recombination of the AA-derived $\mathrm{MA}_{0.5} \mathrm{FA}_{0.5} \mathrm{~Pb}_{0.5} \mathrm{Sn}_{0.5} \mathrm{I}_{3}$ film is more effectively suppressed.

To obtain more in-depth understanding of this phenomenon, trap-state density of both films was measured accordingly. Figure $\mathbf{S 4}$ presents the $I-V$ response of these films in SCLC regime with light bias to simulate the states in device under work condition. Three regions can be divided in the measured $I-V$ curves. At low voltages, the $I-V$ response shows an Ohmic character and, at intermediate voltages, the current starts to show a nonlinear dependence on the applied voltage. Subsequently, a quadratic region appeared, wherein the $I-V$ response can be easily fitted with the Mott's space charge-limited current theory. The kink point of the slopes extracted from the low voltage and intermediate voltage mark the state of completely filled traps.[34-35] Therefore, the trap-filled limit voltage $\left(\mathrm{V}_{\mathrm{TFL}}\right)$ can be correlated with the trap-state density in the formula:

$$
V_{T F L}=\frac{e n_{t} L^{2}}{2 \varepsilon \varepsilon_{0}}
$$


where $e$ is the elementary charge, $n_{t}$ is the trap-state density, $L$ is the thickness of $\mathrm{MA}_{0.5} \mathrm{FA}_{0.5} \mathrm{~Pb}_{0.5} \mathrm{Sn}_{0.5} \mathrm{I}_{3}$ film (herein, $1 \mathrm{~mm}$ ), $\quad \varepsilon \quad$ is the relative dielectric constant of perovskite film (see Experimental Section), and $\varepsilon_{0}$ is the vacuum permittivity. Consequently, the estimated trap-state density of $\mathrm{SnF}_{2}$-derived and AA-derived $\mathrm{MA}_{0.5} \mathrm{FA}_{0.5} \mathrm{~Pb}_{0.5} \mathrm{Sn}_{0.5} \mathrm{I}_{3}$ films is $1.79 \times 10^{16} \mathrm{~m}^{-3}$ and $1.33 \times 10^{16} \mathrm{~m}^{-3}$, respectively. The reduced trap-state density of AA film affirms its prolonged charge carrier lifetime observed in Figure 4 as a result of reduced charge recombination. This validates the positive roles of $\mathrm{AA}$ in retarding $\mathrm{Sn}^{2+}$ oxidation solution (Figure 1) in addition to facilitating film formation (Figure $2 \& \mathbf{3}$ ).

The $\mathrm{MA}_{0.5} \mathrm{FA}_{0.5} \mathrm{~Pb}_{0.5} \mathrm{Sn}_{0.5} \mathrm{I}_{3}$ PVSC was fabricated in an inverted device configuration of ITO/PEDOT:PSS/perovskite/PCBM/bis- $\mathrm{C}_{60} / \mathrm{Ag},[24,36]$ in which the thickness of perovskite was about $350 \mathrm{~nm}$ (as shown in Figure S5). The device using the $\mathrm{SnF}_{2}$-derived $\mathrm{MA}_{0.5} \mathrm{FA}_{0.5} \mathrm{~Pb}_{0.5} \mathrm{Sn}_{0.5} \mathrm{I}_{3}$ film was denoted as Device A, while the one using AA-derived film was named as Device B. Their corresponding photocurrent density-voltage $(J-V)$ characteristics measured under AM $1.5 \mathrm{G}$ irradiation at $100 \mathrm{~mW} / \mathrm{cm}^{2}$ are shown in Figure 5a, wherein the applied voltage scan rate was set at $0.6 \mathrm{~V} / \mathrm{s}$ and the $\mathrm{J}-\mathrm{V}$ curves were recorded under different scan directions. The detailed photovoltaic parameters, i.e., open-circuit voltage $\left(V_{O C}\right)$, fill factor $(\mathrm{FF})$, short-circuit current density $\left(J_{S C}\right)$, and PCE of these fabricated devices are summarized in Table $\mathbf{1}$.

As shown, the Device B yielded a promising $\mathrm{PCE}_{\mathrm{MAX}}$ of $14.01 \%$ with a high $V_{O C}$ of $0.78 \mathrm{~V}$, a $J_{S C}$ of $25.69 \mathrm{~mA} \mathrm{~cm}^{-2}$, and a FF of 0.70 under the forward scan, surpassing the performance (PCE $\mathrm{MAX}_{1}: 12.18 \% ; V_{O C}$ of $0.74 \mathrm{~V} ; J_{S C}$ of $24.57 \mathrm{~mA} \mathrm{~cm}{ }^{-2}$; FF of 0.67 ) of the control Device A. Moreover, Device B showed less hysteresis than Device A. The better photovoltaic performance in Device B clearly suggests that AA-derived $\mathrm{MA}_{0.5} \mathrm{FA}_{0.5} \mathrm{~Pb}_{0.5} \mathrm{Sn}_{0.5} \mathrm{I}_{3}$ film has better film quality since the same charge-transporting layers (CTLs) are used for both devices. This confirms the efficacy of using AA additive to assist processing of $\mathrm{Pb} / \mathrm{Sn}$-based 
perovskites. Unlike the commonly observed hysteresis behavior in Pb-based PVSCs, the PCE obtained under the forward scan is larger than that measured under the reverse scan.[37] The incident photon-to-current conversion efficiency (IPCE) spectra for both devices are shown in Figure 5b. Both devices showed broad photo response, which are in good agreement with their corresponding UV-vis absorption. Figure $\mathbf{5 c}$ and $\mathbf{5 d}$ illustrate the performance histogram of both devices, wherein an $\mathrm{PCE}_{\mathrm{AVG}}$ of $13.25 \pm 0.25 \%$ was achieved for Device $\mathrm{B}$ while a lower value of $10.50 \pm 0.25 \%$ was obtained for Device A, showing the effectiveness of using AA additive in enhancing device performance.

The long-term stability of these fabricated PVSCs was also examined under both inert and ambient conditions. Figure 5e-h depicted the evolution of normalized key parameters as a function of storage time in $\mathrm{N}_{2}$-filled golvebox. Note that the PCE of both devices increased initially then followed by a slow decrease. The similar behavior was observed in pure $\mathrm{Sn}$ based devices.[38] For Device A, a faster decay of PCE is observed after one week storage compared to Device B, mainly contributed by the drop of Voc. Surprisingly, Device B preserves $99 \%$ of its initial PCE after being stored in glovebox for one month, while Device A only has $63 \%$ of its initial value remained. Different to Device A, the degraded PCE of Device B was merely contributed from the decreased $J_{S C}$ while its resultant $V_{O C}$ and FF remained the same. Figure S6 presented the stability of both devices stored in the dark ambient condition (humidity: $\sim 40-60 \%$; temperature: $\sim 20{ }^{\circ} \mathrm{C}$ ). Although both devices decay rapidly, Device B shows better durability in air. These results reveal the great merit of AA additive in slowing down $\mathrm{Sn}$ oxidation in perovskites.

Given the different decay patterns observed for $V_{O C}$ in both devices, the Mott-Schottky (M-S) analysis through capacitance-voltage measurements was performed to further clarify the effect of $\mathrm{Sn}^{2+}$ oxidation on device performance. In general, the built-in potential $\left(U_{b i}\right)$ of a device is determined by the space charge generation at the perovskite/electron-transporting 
material (PCBM herein) and perovskite/hole-transporting material (PEDOT:PSS herein) heterojunction as a result of the different Fermi energy levels.[39] The electric field in the junction assists charge separation and inhibits back electron transfer.[40] Figure 6a showed the M-S plot for both devices measured at $1 \mathrm{kHz}$ with $20 \mathrm{mV}$ amplitude in dark. The $U_{b i}$ in $\mathrm{MA}_{0.5} \mathrm{FA}_{0.5} \mathrm{Sn}_{0.5} \mathrm{~Pb}_{0.5} \mathrm{I}_{3}$ device is only around $0.48 \mathrm{~V}$, much smaller than that of $\mathrm{MAPbI}_{3}$ device (Figure S7). It was documented that the built-in potential will decrease if the Sn ratio increases in the binary metal perovskite films,[41] resulting in poorer charge separation and transport in the derived heterojunction. To display the evolution of device's intrinsic property due to the oxidation of $\mathrm{Sn}^{2+}$, the M-S analysis was also conducted after storing in air for $24 \mathrm{~h}$. The $U_{b i}$ in Device A decreased drastically from $0.45 \mathrm{~V}$ to $0.36 \mathrm{~V}$ while that of device $\mathrm{B}$ showed a negligible difference of $0.03 \mathrm{~V}$. Considering that the same CTLs are used in both devices, the drop in $U_{b i}$ can be considered as the main reason contributes to the significant drop of $V_{O C}$ in device A since the function between $V_{\mathrm{oc}}$ and photogenerated carrier collection efficiency $\left(\eta_{\text {col }}\right)$ follows the formula[42]:

$$
V_{O C}=V_{\text {oC-ideal }}+\left(k_{B} \frac{\mathrm{T}}{\mathrm{q}}\right) \ln \left(\eta_{\text {col }}\right)
$$

where the $V_{O C \text {-ideal }}$ is reached only if the external quantum efficiency is $100 \%, k_{B}$ is the Boltzmann constant, $q$ is the elementary charge, $T$ is the temperature, and the $\eta_{\text {col }}$ is the photogenerated carrier collection efficiency.

For the Sn-based perovskite family, there is a large amount of defects induced by $\mathrm{Sn}^{2+}$ oxidation.[25] These defects could act as carrier trapping sites under the working conditions. To confirm the enhanced stability of Device B over Device A, the trap-state density of both devices was further investigated by admittance measurements.[43] The energetic profile of trap distribution can be derived from the frequency dependent capacitance according to the equation (3)[44-45]: 


$$
N_{t}=-\frac{U_{b i}}{q w_{d}} \times \frac{d C}{d \omega} \times \frac{\omega}{k_{B} T}
$$

where $C$ is capacitance, $\omega$ is the angular frequency, and $U_{b i}$ and $W_{d}$ are built-in potential and depletion width, respectively, extracted from the corresponding M-S plot. As shown in Figure 6b, for both fresh devices, the relative trap-state density is similar, however, it increased after exposing to air for 24h. The trap-state density in Device A is almost 3 order of magnitude higher than that in Device B after $24 \mathrm{~h}$ air exposure. This result clearly manifests that AA could efficiently prevent trap formation in device due to its capability in retarding $\mathrm{Sn}^{2+}$ oxidation.

\section{Conclusion}

In summary, we have discovered a simple but effective solvent additive, ascorbic acid (AA), to enable fabrication of efficient and stable $\mathrm{Pb} / \mathrm{Sn}$-based binary PVSCs. AA as an antioxidant not only retards the $\mathrm{Sn}^{2+}$ oxidation in perovskites but also modulates its film formation and crystallization to significantly improve the optoelectronic quality of binary pervoskite films. This is evidenced by the prolonged photogenerated carrier lifetime (182.7 ns) of derived $\mathrm{MA}_{0.5} \mathrm{FA}_{0.5} \mathrm{~Pb}_{0.5} \mathrm{Sn}_{0.5} \mathrm{I}_{3}$ film. As a result, $\mathrm{MA}_{0.5} \mathrm{FA}_{0.5} \mathrm{~Pb}_{0.5} \mathrm{Sn}_{0.5} \mathrm{I}_{3}$ processed with AA enables device to obtain a high PCE of $14.01 \%$ and better stability, outperforming those of the control device using $\mathrm{SnF}_{2}$ additive. This study provides a new approach to enhance the performance and stability of $\mathrm{Pb} / \mathrm{Sn}$ binary PVSCs.

\section{Acknowledgment}

This work was supported by the Asian Office of Aerospace R\&D (FA2386-15-1-4106), the

Office of Naval Research (N00014-14-1-0246), the National Science Foundation (DMR-1608279), and the Department of Energy SunShot (DE-EE0006710). Alex K.-Y. Jen 
thanks the Boeing-Johnson Foundation for their financial support. Zhibin Yang thanks the financial support from the State of Washington through the University of Washington Clean Energy Institute. The authors also thank Francis Lin, Ting Zhao, and Zhuoyu Peng for material synthesis, thank Xueliang Shi for the NMR measurement.

\section{References}

[1] A. Kojima, K. Teshima, Y. Shirai, T. Miyasaka, J. Am. Chem. Soc. 131(2009) 6050-6051.

[2] http://www.nrel.gov/pv/assets/images/efficiency_chart.jpg

[3] N. Pellet, P. Gao, G. Gregori, T. Yang, M. Nazeeruddin, J. Maier, M. Grätzel, Angew. Chem. Int. Ed. 53(2014) 3151-3157.

[4] K. Hwang, Y. Jung, Y. Heo, F. Scholes, S. Watkins, J. Subbiah, D. Jones, D. Kim, D. Vak, Adv. Mater. 27(2015) 1241-1247.

[5] H. Snaith, J. Phys. Chem. Lett. 4(2013) 3623-3630.

[6] X. Xu, S. Li, H. Zhang, Y. Shen, S. Zakeeruddin, M. Graetzel, Y. Cheng, M. Wang, ACS Nano 9(2015) 1782-1787.

[7] S. D. Stranks, G. E. Eperon, G. Grancini, C. Menelaou, M. J. P. Alcocer, T. Leijtens, L. M. Herz, A. Petrozza, H. J. Snaith, Science 342(2013) 341-344.

[8] G. Xing, N. Mathews, S. Sun, S. Lim, Y. Lam, M. Grätzel, S. Haisalkar, T. Sum, Science 342(2013) 344-347.

[9] M. Lee, J. Teuscher, T. Miyasaka, T. Murakami, H. Snaith, Science 338(2012) 643-647.

[10] S. T. Williams, A. Rajagopal, C.-C. Chueh, A. K.-Y. Jen, J. Phys. Chem. Lett. 7(2016) 811-819.

[11] N. Espinosa, L. Serrano-Luján, A. Urbina, F. Krebs, Solar Energy Materials \& Solar Cells 137(2015) 303-310.

[12] J. Gong, S. Darling, F. You, Energy Environ. Sci. 8(2015) 1953-1968. 
[13] J. Xu, Y. Chen, L. Dai, Nat. Commun. 6(2015) 8103.

[14] Y. Chen, T. Chen, L. Dai, Adv. Mater. 27(2015) 1053-1059.

[15] Z. Wang, Z. Shi, T. Li, Y. Chen, W. Huang, Angew. Chem. Int. Ed. 56(2017) 1190-1212.

[16] A. Babayigit, A. Ethirajan, M. Muller, B. Conings, Nat. Mater. 15(2016) 247-251.

[17] M. Kumar, S. Dharani, W. Leong, P. P. Boix, R. Prabhakar, T. Baikie, C. Shi, H. Ding, R.

Ramesh, M. Asta, M. Graetzel, S. G. Mhaisalkar, N. Mathew, Adv. Mater. 26(2014) $7122-7127$.

[18] N. K. Noel, S. D. Stranks, A. Abate, C. Wehrenfennig, S. Guarnera, A.-A. Haghighirad, A. Sadhanala, G. E. Eperon, S. K. Pathak, M. B. Johnston, A. Petrozza, L. M. Herz, H. Snaith, Energy Environ. Sci. 7(2014) 3061-3068.

[19] Y. Ogomi, A. Morita, S. Tsukamoto, T. Saitho, N. Fujikawa, Q. Shen, T. Toyoda, K. Yoshino, S. S. Pandey, T. Ma, S. Hayase, J. Phys. Chem. Lett. 5(2014) 1004-1011.

[20] F. Zuo, S. T. Williams, P.-W. Liang, C.-C. chueh, C.-Y. Liao, A. K-Y. Jen, Adv. Mater. 26(2014) 6454-6460.

[21] F. Hao, C. C. Stoumpos, R. P. H. Chang, M. G. Kanatzis, J. Am. Chem. Soc. 136(2014) 8094-8099.

[22] Y. Li, W. Sun, W. Yan, S. Ye, H. Rao, H. Peng, Z. Zhao, Z. Bian, Z. Liu, H. Zhou, C. Huang, Adv. Energy Mater. 6(2016) 1601353.

[23] W. Liao, D. Zhao, Y. Yu, N. Shrestha, K. Ghimire, C. R. Grice, C. Wang, Y. Xiao, A. J. Cimaroli, R. J. Ellingson, N. J. Podraza, K. Zhu, R. Xiong, Y. Yan, J. Am. Chem. Soc. 138(2016) 12360-12363.

[24] Z. Yang, A. Rajagopal, C. Chueh, S. Jo, B. Liu, T. Zhao, A. K-Y. Jen, Adv. Mater. 28(2016) 8990-8997.

[25] G. E. Eperon, T. Leijtens, K. A. Bush, R. Prasanna, T. Green, J. Wang, D. P. McMeekin, G. Volonakis, R. L. Milot, R. May, A. Palmstrom, D. J. Slotcavage, R. A. Belisle, J.B. Patel, E. S. 
Parrott, R. J. Sutton, W. Ma, F. Moghadam, B. Conings, A. Babayigit, H.-G. Boyen, S. Bent, F. Giustino, L. M. Herz, M. B. Johnston, M. D. McGehee, H. J. Snaith, Science 354(2016) 861-865.

[26] S. Lee, S. Shin, Y. Kim, D. Kim, T. Ahn, J. Noh, J. Seo, S. Seok, J. Am. Chem. Soc. 138(2016) 3974-3977.

[27] A. B. Volynsky, E. M. Sedykh, L. N. Bannykh, Talanta 38(1991) 761-765.

[28] J.-W. Lee, H.-S. Kim, N.-G. Park, Acc. Chem. Res. 49(2016) 311-319.

[29] Z. Li, H. Chen, H. Bao, M. Gao, Chem. Mater. 16(2004) 1391-1393.

[30] Q. Xiong, J. Tu, S. Shi, X. Liu, X. Wang, C. Gu, J. Power Sources 256(2014) 153-159.

[31] N. Jeon, J. Noh, Y. Kim, W. Yang, S. Ryu, S. Seok, Nat. Mater. 13(2014) 897-903.

[32] Y. Guo, K. Shoyama, W. Sato, E. Nakamura, Adv. Energy Mater. 6(2016) 1502317.

[33] F. Wang, J. Ma, F. Xie, L. Li, J. Chen, J. Fan, N. Zhao, Adv. Funct. Mater. 26(2016) $3417-3423$

[34] D. Shi, V. Adinolfi, R. Comin, M. Yuan, E. Alarousu, A. Buin, Y. Chen, S. Hoogland, A. Rothenberger, K. Katsiev, Y. Losovyj, X. Zhang, P. A. Dowben, O. F. Mohammed, E. H. Sargent, O. M. Bakr, Science 347(2015) 519-522.

[35] Q. Han, S.-H. Bae, P. Sun, Y.-T. Hsieh, Y. Yang, Y. Rim, H. Zhao, Q. Chen, W. Shi, G. Li, Y. Yang, Adv. Mater. 28(2016) 2253-2258.

[36] X. Liu, Z. Yang, C. C. Chueh, A. Rajagopal, S. T. Williams, Y. Sun, A. K.-Y. Jen, J. Mater. Chem. A 4(2016) 17939-17945.

[37] H.-S. Kim, N.-G. Park, J. Phys. Chem. Lett. 5(2014), 2927-2934.

[38] W. Li, J. Li, J. Li, J. Fan, Y. Mai, L. Wang, J. Mater. Chem. A 4(2016) 17104-17110.

[39] W. A. Laban, L. Etgar, Energy Environ. Sci. 6(2013) 3249-3253.

[40] D. Barkhouse, R. Debnath, I. Kramer, D. Zhitomirsky, A. Pattantyus-Abraham, L. Lvina, L. Etgar, M. Grätzel, E. Sargent, Adv. Mater. 23(2011) 3134-3138. 
[41] H. Feng, T. R. Paudel, E. Y. Tsymbal, X. Zeng, J. Am. Chem. Soc. 137(2015) 8227-8236.

[42] M. Grätzel, Nat. Mater. 13(2014) 838-842.

[43] Y. Shao, Z. Xiao, C. Bi, Y. Yuan, J. Huang, Nat. Commun. 5(2014) 5784.

[44] R. Herberholz, M. Igalson, H. W. Schock, J. Appl. Phys. 83(1998) 318-325.

[45] T. Walter, R. Herberholz, C. Müller, H. W. Schock, J. Appl. Phys. 80(1996) 4411-4420. 


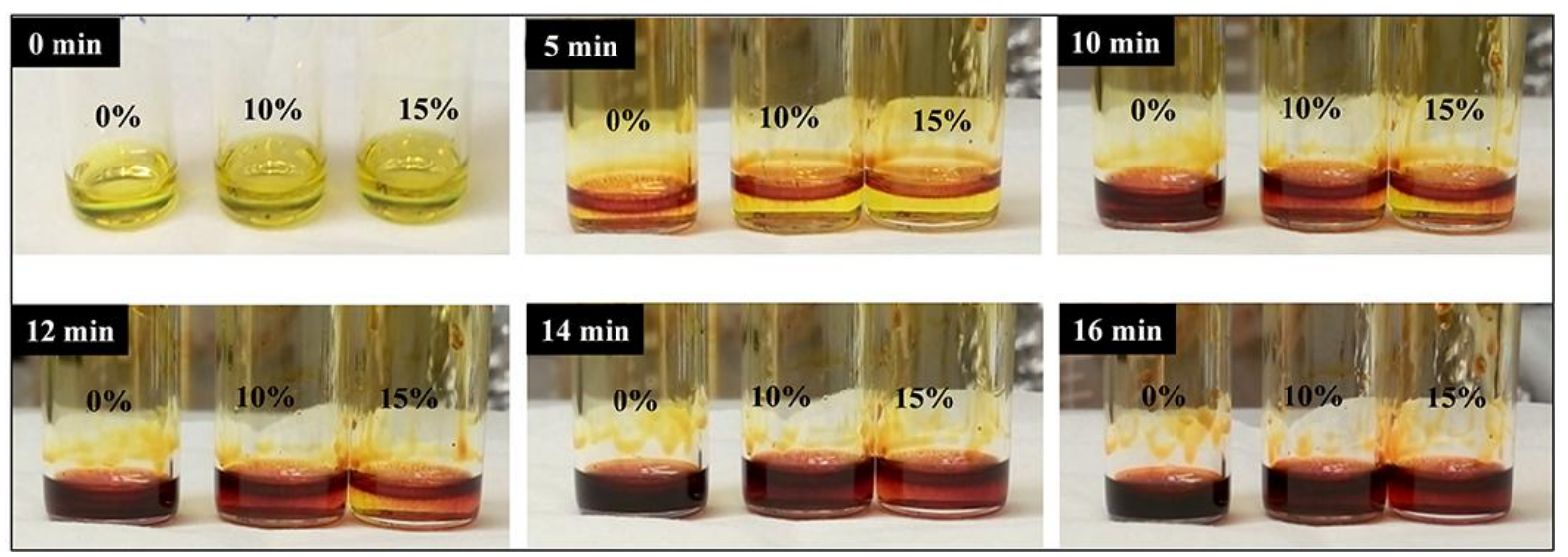

Figure 1 Photographs of $\mathrm{FASnI}_{3}$ precursor solutions containing $1 \mathrm{mmol} \mathrm{SnI}_{2}, 1 \mathrm{mmol} \mathrm{FAI}$, and $0.1 \mathrm{mmol} \mathrm{SnF}_{2}$ in a mixed solvent of $\mathrm{DMF} / \mathrm{DMSO}(4: 1)$ with varied mol\% of AA.
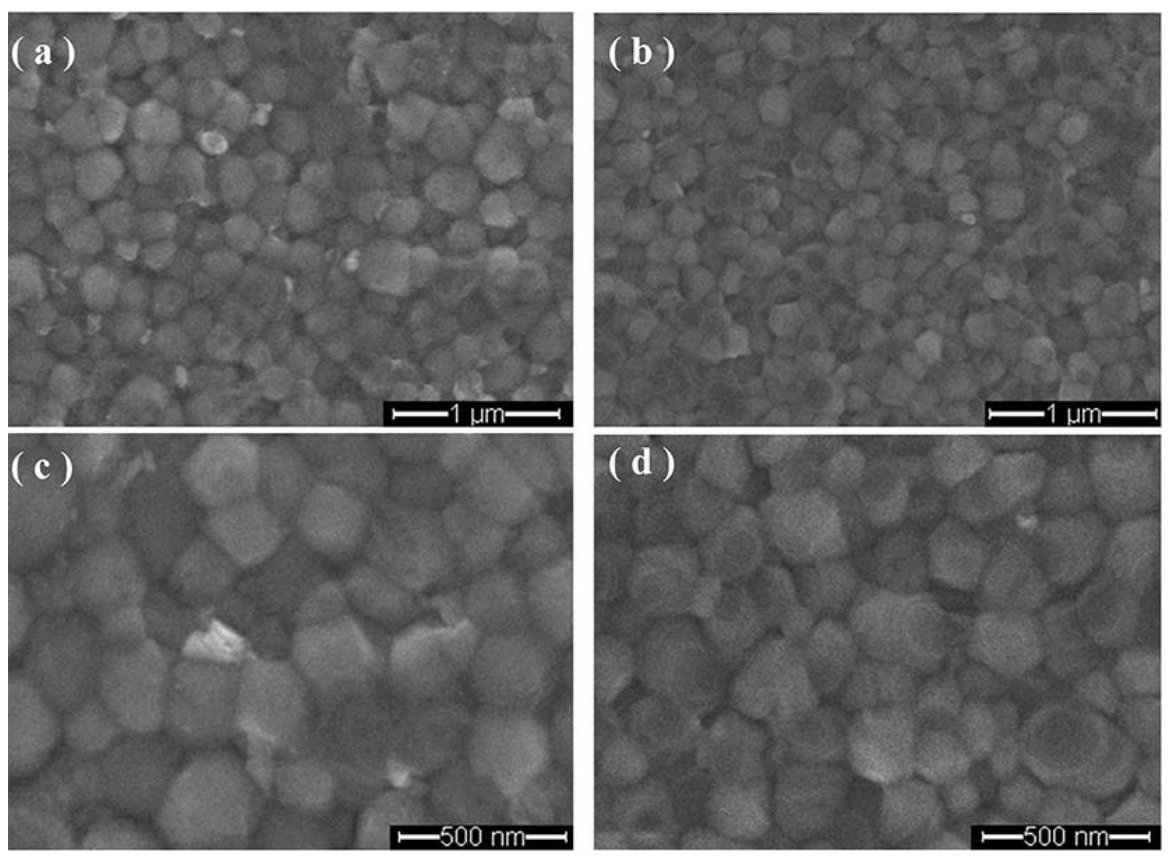

Figure 2. Top-view SEM images of $\mathrm{MA}_{0.5} \mathrm{FA}_{0.5} \mathrm{~Pb}_{0.5} \mathrm{Sn}_{0.5} \mathrm{I}_{3}$ processed with (a \& c) $\mathrm{SnF}_{2}$ and (b \& d) AA additives (molar ratio to $\mathrm{SnI}_{2}, 10 \%$ ) in different magnifications. 
(a)

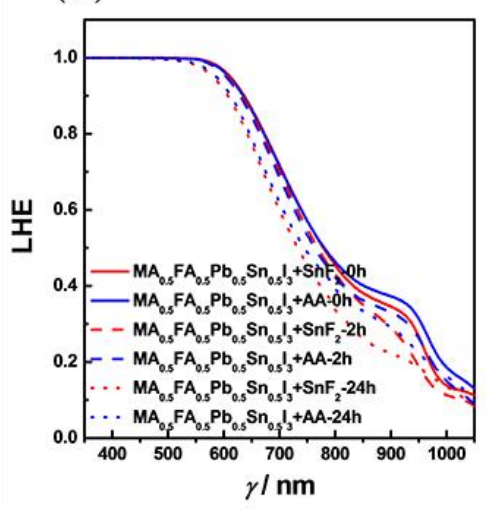

( b )

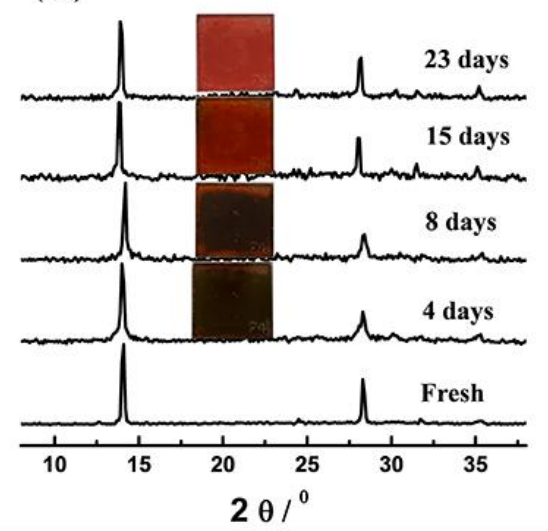

(c)

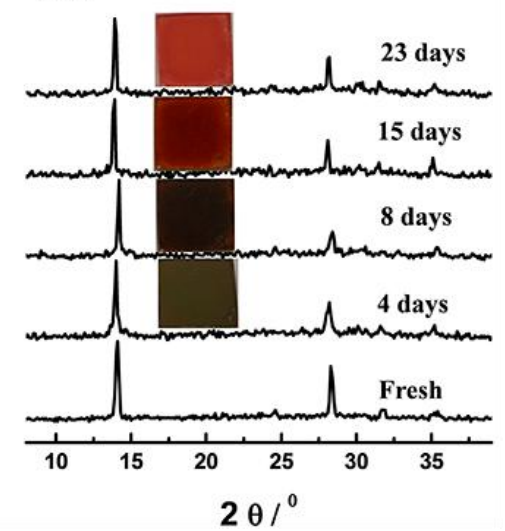

Figure 3 (a) Light-harvesting efficiency (LHE) of the studied $\mathrm{MA}_{0.5} \mathrm{FA}_{0.5} \mathrm{~Pb}_{0.5} \mathrm{Sn}_{0.5} \mathrm{I}_{3}$ films and XRD profiles of the $\mathrm{MA}_{0.5} \mathrm{FA}_{0.5} \mathrm{~Pb}_{0.5} \mathrm{Sn}_{0.5} \mathrm{I}_{3}$ film processed with (b) $\mathrm{SnF}_{2}$ and (c) $\mathrm{AA}$ additives in air (humidity: 40-60\%; temperature: $\sim 2{ }^{\circ} \mathrm{C}$ ).

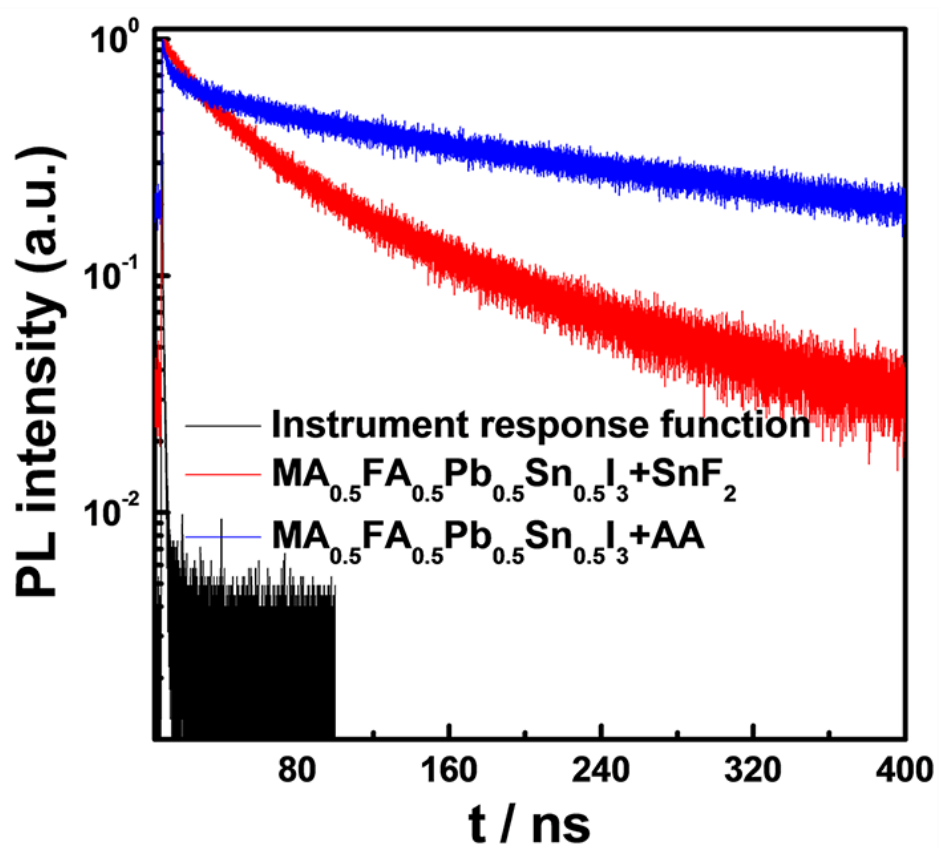

Figure 4. PL decay curves of studied perovskite films on glass. The black plot is the instrument response function. 

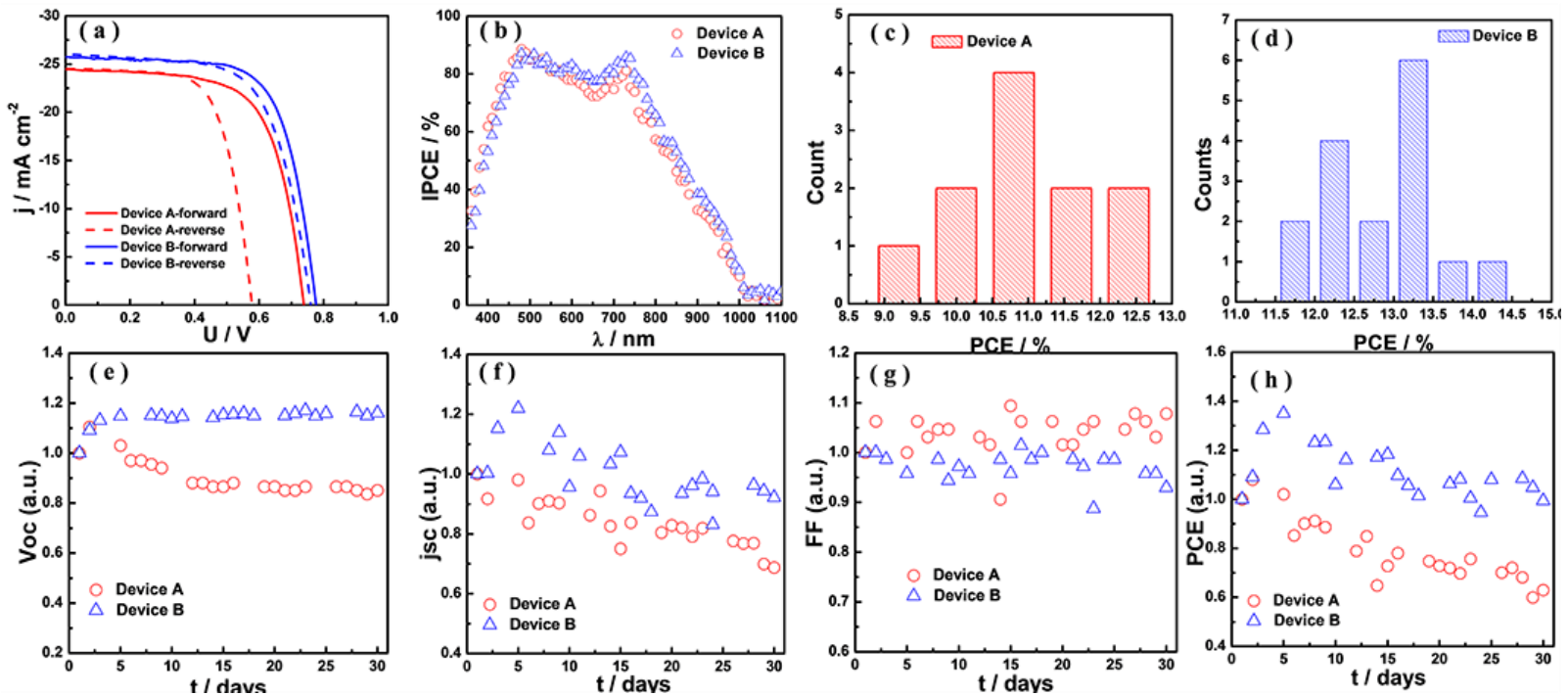

Figure 5. (a) $J-V$ characteristics of the studied PVSCs recorded under forward scan with a scan rate of $0.6 \mathrm{~V} / \mathrm{s}$. (b) IPCE spectrum and (c \& d) PCE histogram of the studied PVSCs. (e-h) The evolution of photovoltaic parameters for both devices as a function of storage time in $\mathrm{N}_{2}$-filled glovebox.

( a )

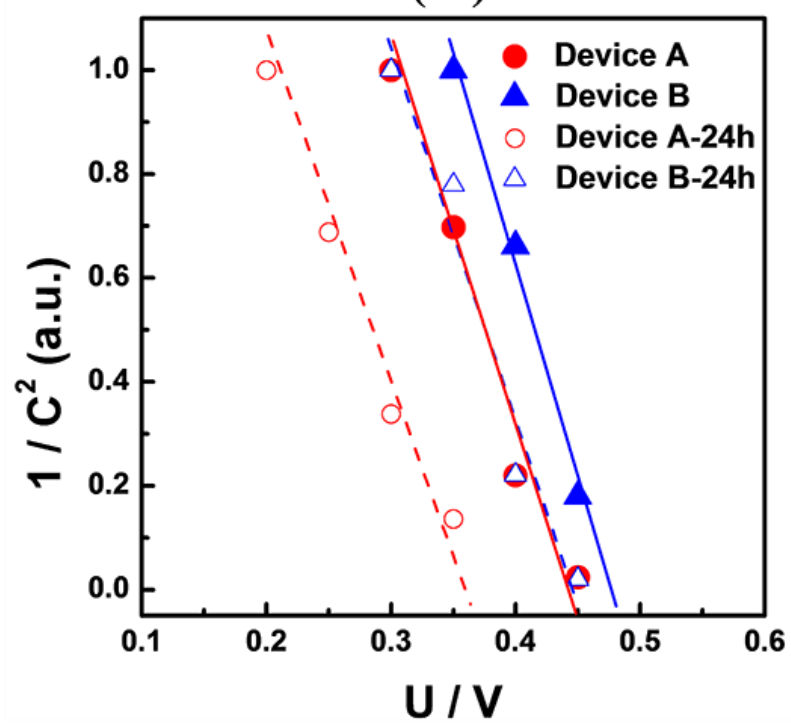

( b )

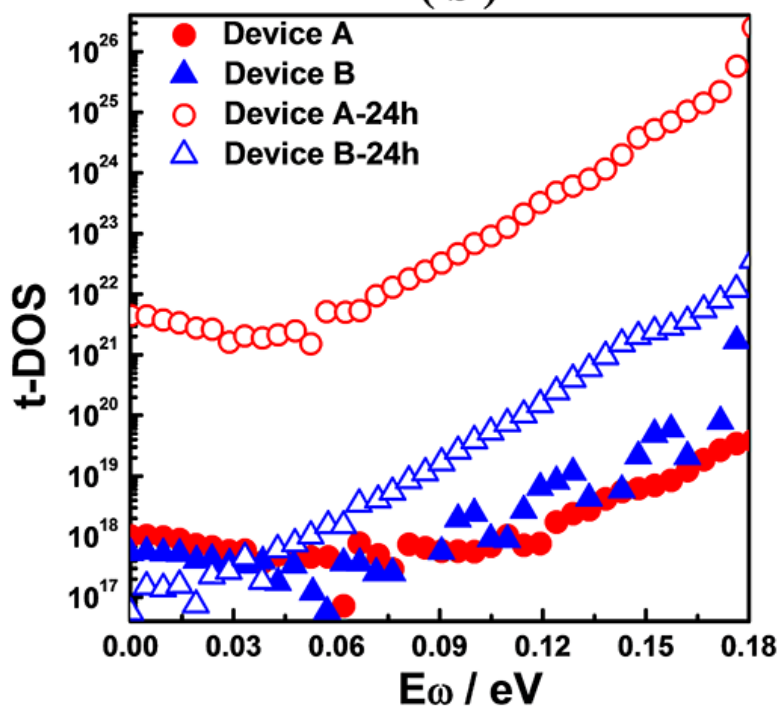

Figure 6. Electric analysis for complete device. a) Mott-Schottky analysis of device A and B with different time at $1 \mathrm{kHz}$ with $20 \mathrm{mV}$ amplitude in the dark, b) trap density of state obtained by the admittance spectroscopy for devices at $0 \mathrm{~V}$ bias with $20 \mathrm{mV}$ amplitude in dark from $200 \mathrm{KHz}$ to $10 \mathrm{mHz}$. 
Table 1 Detailed photovoltaic parameters of the champion Device A \& B under different scan directions at $0.6 \mathrm{~V} / \mathrm{s}$ under AM $1.5 \mathrm{G}$ illumination $\left(100 \mathrm{~mW} \mathrm{~cm}^{-2}\right.$ light intensity).

\begin{tabular}{cccccc}
\hline & & $\boldsymbol{J}_{S C} / \mathbf{m A ~ c m}^{-2}$ & $V_{O C} / \mathbf{V}$ & FF & PCE \\
\hline \multirow{2}{*}{ Device A } & Form $\boldsymbol{J}_{S C}$ to $\boldsymbol{V}_{\boldsymbol{O}} / \boldsymbol{\%}$ & 24.57 & 0.74 & 0.67 & 12.18 \\
& Form $\boldsymbol{V}_{\boldsymbol{O}}$ to $\boldsymbol{J}_{\boldsymbol{S C}}$ & 24.51 & 0.58 & 0.67 & 9.55 \\
\hline \multirow{2}{*}{ Device B } & Form $\boldsymbol{J}_{S C}$ to $\boldsymbol{V}_{\boldsymbol{O}}$ & 25.69 & 0.78 & 0.70 & 14.01 \\
& Form $\boldsymbol{V}_{\boldsymbol{O}}$ to $\boldsymbol{J}_{S C}$ & 26.00 & 0.76 & 0.66 & 12.98 \\
\hline
\end{tabular}


Ascorbic acid was for the first time introduced as an effective antioxidant additive to enhance the efficiency and stability of Sn-based perovskite solar cells. It not only can effectively hinder the precursor solution of Sn-based perovskite from oxidation but modulate the Sn-based perovskite crystallization via forming associated intermediate complexes. A high PCE of $14.01 \%$ with improved stability can be finally realized in a $\mathrm{MA}_{0.5} \mathrm{FA}_{0.5} \mathrm{~Pb}_{0.5} \mathrm{Sn}_{0.5} \mathrm{I}_{3}$ PVSC processed with AA additive, outperforming the value $(12.18 \%)$ of the control device processed with the regular $\mathrm{SnF}_{2}$ additive.

Keywords: $\mathrm{Sn}^{2+}$ oxidation, Perovskite solar cell, Ascorbic acid, Stability

X. Xu, C.-C. Chueh, Z. Yang, A. Rajagopal, J. Xu, S. B. Jo \& A. K.-Y. Jen*

Ascorbic Acid as An Effective Antioxidant Additive to Enhance the Efficiency and Stability of Pb/Sn-based Binary Perovskite Solar Cells

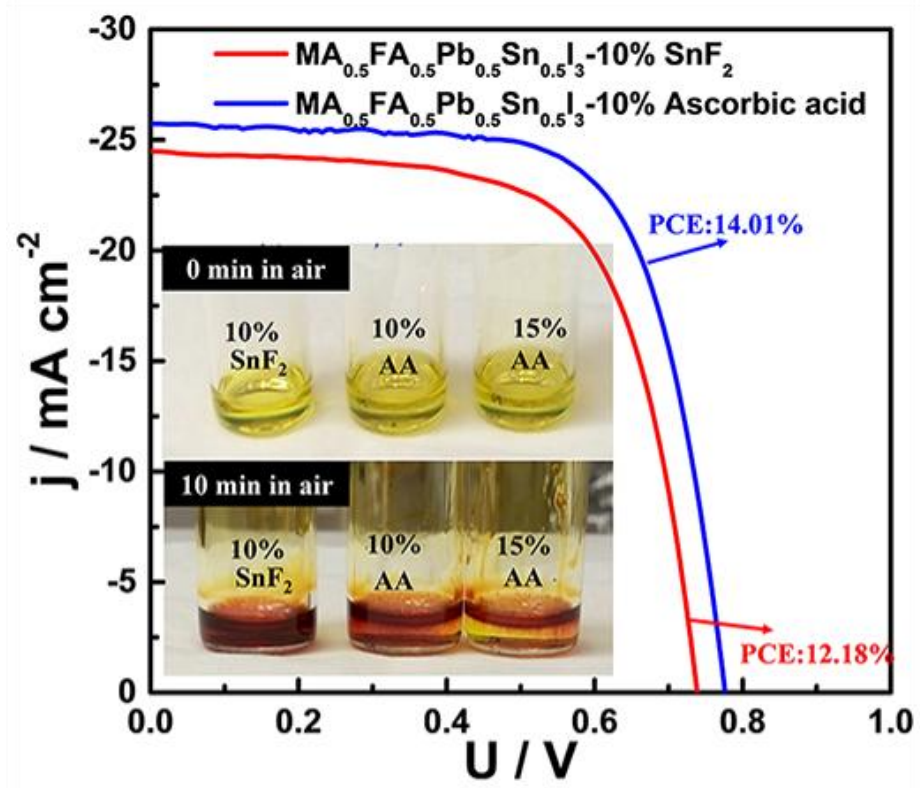

